\title{
Successive ionic layer deposition (SILD) as a new sensor technology: synthesis and modification of metal oxides*
}

\author{
G Korotcenkov ${ }^{1}$, V Tolstoy ${ }^{2}$ and J Schwank ${ }^{3}$ \\ ${ }^{1}$ Laboratory of Micro- and Optoelectronics, Technical University of Moldova, \\ Bld Stefan cel Mare, 168, Chisinau, 2004, Republic of Moldova \\ ${ }^{2}$ Department of Chemistry, St Petersburg State University, St Petersburg, Russia \\ ${ }^{3}$ Department of Chemical Engineering, University of Michigan, Ann Arbor, USA \\ E-mail: ghkoro@yahoo.com
}

Received 21 November 2005, in final form 26 April 2006

Published 7 June 2006

Online at stacks.iop.org/MST/17/1861

\begin{abstract}
In this paper, we have discussed both peculiarities and advantages of successive ionic layer deposition (SILD) methods for the synthesis and modification of metal oxides. For these purposes, the results of research into the design of SILD technology suitable for preparing porous nanostructure $\mathrm{SnO}_{2}$ films and the surface modification of $\mathrm{SnO}_{2}$ films deposited by spray pyrolysis have been analysed. It has been shown that this new method can be used for the deposition of metal oxides and for noble metals. A great deal of interest in the SILD method may be generated by the method's simplicity, cheapness, and ability to deposit thin nanostructure films on rough surfaces. The SILD method essentially consists of successive treatments of both conductive and dielectric substrates by solutions of various salts, which form poorly soluble compounds at the substrate surface. It has been found that SILD technology is an effective method for improving gas sensor parameters. For example, it has been established that surface modification by Pd and Ag using SILD technology improves the gas response of $\mathrm{SnO}_{2}$-based sensors to reducing gases, and depresses their sensitivity to oxidizing gases.
\end{abstract}

Keywords: Layer by layer deposition, metal oxides, $\mathrm{SnO}_{2}$, noble metals, structure characterization, modification, gas response.

\section{Introduction}

Progress in catalysis and gas sensing techniques cannot proceed without extensive knowledge of the nanoscale architecture of active sites at the catalyst or gas sensing surfaces. In order to optimize performance of these materials, it is necessary to develop a strategy to master their surface properties. In particular, active sites need to be formed and stabilized in their more active and selective configurations in order to allow better control of the catalytic and gas sensing processes. The synthesis of sequentially added nanolayers of noble metals and special inorganic compounds with a

* This article was presented at the 13th International Conference on Sensors and Their Applications, held in Chatham, Kent, on 6-7 September 2005. prescribed composition and thickness on the surface of standard catalytic and gas sensing materials (metal oxides) is one of the paramount problems in the preparative chemistry of solids for these purposes [1,2]. This is because such nanolayers significantly alter a number of important properties of the surface, and so are used in the preparation of sorbents, catalysts, and gas sensing materials. For example, such optimization is necessary for the improvement of sensitivity, selectivity and temporal stability of electrical responses of gas sensors. For these purposes, various additives may be used. Elements such as noble metals ( $\mathrm{Ag}, \mathrm{Au}, \mathrm{Pd}, \mathrm{Pt})$, transition metals ( $\mathrm{Fe}, \mathrm{Mn}, \mathrm{Co}, \mathrm{Ni}, \mathrm{Mo}, \mathrm{Cu}$ ), oxides of $\mathrm{W}, \mathrm{Ti}, \mathrm{P}$, and so on can be applied depending on the required result $[1,2]$. These additives can act as promoters, catalysts, surface sites 
for adsorption of oxygen and detected gas with the spill over of adsorbed species, or as elements promoting the improvement of the porosity of the gas sensing matrix and the thermal stability of powders and film microstructures.

Various methods can be used in the preparation of nanolayers and the incorporation of a second component into the metal oxide. Many methods have already been tested for this purpose, for example, bulk doping during calcination, sol-gel technology, spray pyrolysis deposition, thermal evaporation, chemical vapour deposition (CVD), laser ablation, magnetron sputtering, electroless deposition. With the help of these methods, it was possible to form nanoscaled clusters of various components with sizes from $0.1-8 \mathrm{~nm}$ at the surface of metal oxides [1].

However, in many cases these traditional approaches were not effective. Thin film deposition methods such as CVD, MOCVD, molecular beam epitaxy (MBE), magnetron sputtering, or vacuum evaporation, are very cumbersome and inefficient for the deposition of complex materials. The difficulty in uniformly depositing layers of various substances on the surface of dispersed particles, especially with materials such as nanoscaled powders and highly porous materials, is another great limitation of most of the standard deposition methods. Using other standard methods, for example electroless deposition, it is difficult to completely control the deposition of the layers with a small thickness, especially in the $\mathrm{nm}$ range of sizes. The complexity and high cost of these traditional film deposition techniques severely limit the ability to systematically experiment with the modification of film composition over wide ranges and to quickly identify film compositions with optimum gas sensing and catalytic characteristics. This also limits the ability to systematically study the nature of gas sensitive and catalytic effects. Consequently, the selection of suitable base materials, metal catalysts, promoters and additives relies on a time consuming and costly empirical approach. When the method of bulk doping (the sol-gel method) is used, the changes of both structural and electrophysical properties take place simultaneously with the surface modification. As a result, the problems of understanding the role of surface modification in catalytic and gas sensing phenomena appear during model experiments. In addition, sol-gel deposition involves a multistage process of long duration.

Therefore, the development of new or improved materials for catalysis and gas sensor applications requires a search for novel and innovative approaches to the nanoscale design of these materials. The use of the technology of surface modification by successive ionic layer deposition (SILD) method is such an innovative approach. This method was first suggested by Nicolau and Tolstoy [4-6] in order to form sulphide layers and metal oxides. It is necessary to note that this method was often called successive ion layer adsorption and reaction (SILAR) in other scientific literature [3, 5, 6]. The name SILD, which we use, fits in better with the names of methods of thin films synthesis, such as CVD, MOCVD, ALD (atomic layer deposition), and more adequately reflects the essence of this method.

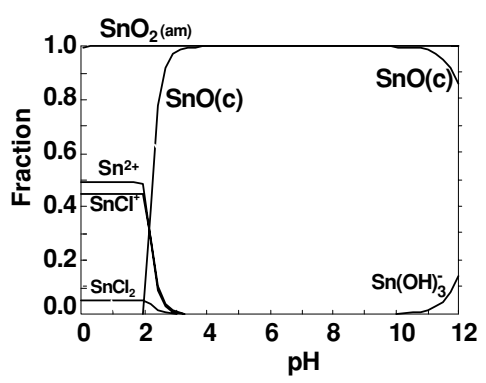

Figure 1. Diagram of hydro-complexes Sn(II) and Sn(IV) distribution depending on $\mathrm{pH}$ solution during SILD. In this figure $\mathrm{SnO}_{2}(\mathrm{am})$ and $\mathrm{SnO}(\mathrm{c})$ are $\mathrm{Sn}(\mathrm{OH})_{4}=\mathrm{SnO}_{2} \cdot n \mathrm{H}_{2} \mathrm{O}$ and $\mathrm{Sn}(\mathrm{OH})_{2}$, in colloidal amorphous forms respectively.

\section{Peculiarities of SILD technology}

The distinguishing characteristic of the SILD method is the use of alternating aqueous solutions of a metal salt solution followed by a hydrolyzing or sulphidizing solution. The SILD method essentially consists of iterative successive treatments of the substrate surface with a solution of various salts such as acetates, chlorides and nitrates of various metals [3, 7, 8]. A significant limitation in the SILD of oxide thin films seems to be that after repeated treatment of the growing film (which is necessary for the synthesis of the next layer), the film becomes partially redissolved in the solution of the metal salt. To resolve this problem, Tolstoy $[4,9]$ suggested the use of a metal salt in a lower oxidation state. For example, in the synthesis of $\mathrm{SnO}_{2} \cdot n \mathrm{H}_{2} \mathrm{O}$ layers in [10], a $0.1-0.0001 \mathrm{M}$ solution of $\mathrm{SnF}_{2}$ and $3 \% \mathrm{H}_{2} \mathrm{O}_{2}(\mathrm{pH} \approx 8-9)$ with $\mathrm{KOH}$ additives as reagents was chosen in order to attain irreversible synthesis conditions. Hydrogen peroxide transformed the adsorbed cations $\mathrm{Sn}^{2+}$ in $\mathrm{Sn}^{4+}$, which were forming $\mathrm{Sn}(\mathrm{OH})_{4}$ in an alkaline environment. The analysis of the results of $\mathrm{Sn}^{2+}$ and $\mathrm{Sn}^{4+}$ hydroxides deposition from $0.01 \mathrm{M} \mathrm{SnF}_{2}$ solutions, defined using both the data base and a program for hydro-chemical calculations [11] is shown in figure 1 . From this figure, it can be concluded that $100 \% \mathrm{SnO}(\mathrm{c})$ deposition is observed at a $\mathrm{pH} \approx 2$, while $\mathrm{Sn}(\mathrm{OH})_{4}$ deposition is observed at a $\mathrm{pH} \approx 0$. The $\mathrm{SnO}_{2} \cdot \mathrm{H}_{2} \mathrm{O}$ layer synthesized during the treatment in alkali solution with an oxidizer will not be dissolved by further treatment by a $\mathrm{Sn}^{2+}$ salt solution.

The above mentioned process of $\mathrm{SnO}_{2} \cdot n \mathrm{H}_{2} \mathrm{O}$ layer synthesis by the SILD method may be described as follows. The adsorption of $\mathrm{SnOH}^{+}$ions takes place in water solutions at the surface of the silica at a $\mathrm{pH} \approx 2$. However, after removal of the excess salt by rinsing in water, a layer of adsorbed hydrate $\mathrm{Sn}(\mathrm{II})$ is formed on the surface:

$$
\equiv \mathrm{SiO}^{-}+\mathrm{SnOH}^{+} \rightarrow \equiv \mathrm{SiOSnOH} \text {. }
$$

The transition of $\mathrm{Sn}(\mathrm{II}) \rightarrow \mathrm{Sn}(\mathrm{IV})$ takes place in the treatment of the weak alkaline solution of $\mathrm{H}_{2} \mathrm{O}_{2}$ stage:

$$
\equiv \mathrm{SiOSnOH}+\mathrm{H}_{2} \mathrm{O}_{2} \rightarrow \equiv \operatorname{SiOSn}(\mathrm{OH})_{3} \cdot n \mathrm{H}_{2} \mathrm{O}_{2} \text {. }
$$

During treatment in the $\mathrm{SnF}_{2}$ solution in the second SILD cycle, the hydroxide $\mathrm{Sn}(\mathrm{IV})$ is not dissolved, and the ions of $\mathrm{SnOH}^{+}$are adsorbed on its surface. Thus, after carrying out repeated SILD cycles, a layer of $\mathrm{Sn}(\mathrm{OH})_{4}$ hydroxide is formed on the work surface. 
The SILD method is therefore based on the adsorption of firstly cations, and then anions from solutions, whose interactions at the substrate surface produce poorly soluble compounds, such as hydroxides, peroxides and oxides hydrates. In other words, the SILD chemistry includes processes such as the hydroxylation of a growing layer, protonmetal cation exchange between the hydroxylated layer and the water solution, and additional oxidation by hydrogen peroxide, resulting in a higher oxidation state of the chemisorbed metal ion and the formation of poorly soluble peroxicomplexes.

However, the route described is not a unique method for the achievement of irreversible synthesis conditions. At the present time, we have established six routes for the synthesis of hard to dissolve hydrated metal-oxygen compounds [7, 8]. They are

(1) the reactions of adsorbed metal cations with $\mathrm{H}_{2} \mathrm{O}_{2}\left(\mathrm{OH}^{-}\right)$, which was used to synthesize $\mathrm{CuO}_{1+x}, \mathrm{ZnO}_{1+x}$, and $\mathrm{La}(\mathrm{OH})_{x}(\mathrm{OOH})_{y}$;

(2) the oxidation of the adsorbed metal layer by a $\mathrm{H}_{2} \mathrm{O}_{2}$ solution, resulting in the subsequent formation of a layer of the metal peroxide (e.g. $\mathrm{Ce}(\mathrm{OH})_{x}(\mathrm{OOH})_{4-x}$ layers), metal oxides $\left(\mathrm{SnO}_{2} \cdot n \mathrm{H}_{2} \mathrm{O}, \mathrm{Ti}_{2} \mathrm{O}_{3} \cdot n \mathrm{H}_{2} \mathrm{O}\right)$ or metal hydroxides $(\mathrm{FeOOH})$;

(3) the reactions of the adsorbed metal cation $\left(\mathrm{La}_{\mathrm{aq}}^{3+}\right)$ with peroxianion $\left(\mathrm{NbO}_{8}^{3-}\right)$ with the formation of the hard to dissolve $\mathrm{La}_{x} \mathrm{NbO}_{y} \cdot n \mathrm{H}_{2} \mathrm{O}$ compound;

(4) the oxidation of the adsorbed metal cation $\left(\mathrm{Ce}_{\mathrm{aq}}^{3+}\right)$ by the peroxianion $\left(\mathrm{NbO}_{8}^{3-}\right)$ which is followed by the interaction and formation of $\mathrm{Ce}_{x} \mathrm{NbO}_{\mathrm{y}} \cdot n \mathrm{H}_{2} \mathrm{O}$

(5) the reduction of the adsorbed anions by cations (e.g. the reduction of $\mathrm{MnO}_{4}$ by $\mathrm{Mn}^{2+}$ leads to the formation of a $\mathrm{MnO}_{2} \cdot n \mathrm{H}_{2} \mathrm{O}$ layer, and the reduction of $\mathrm{MoO}_{4}^{2-}$ by a $\mathrm{SnCl}_{2}$ solution results in the formation of $\mathrm{Sn}_{x} \mathrm{MoO}_{y} \cdot n \mathrm{H}_{2} \mathrm{O}$ );

(6) the reduction of the adsorbed anions of heteropoly oximetalates (the $\mathrm{H}_{7} \mathrm{PW}_{12} \mathrm{O}_{42}$ reduced by a $\mathrm{SnCl}_{2}$ solution transforms into the hybrid isopoly ( $\mathrm{Sn}-\mathrm{O})$-heteropoly $(\mathrm{H}-$ $\mathrm{P}-\mathrm{W}-\mathrm{O}-$ ) compound).

Therefore, in order to resolve a specific problem, we propose to oxidize the metal ions during film formation, or for cations such as $\mathrm{Cu}^{2+}, \mathrm{Zn}^{2+}$, or $\mathrm{La}^{3+}$, we propose to synthesize the poorly soluble layer of the hydroxides-peroxides. It is convenient to use a special automatic plant to achieve the SILD method. Figure 2 shows the scheme for one designed for the synthesis of metal oxide and noble metal layers on the surface of monolithic substrates. It contains chemical cups (2-5) with different reagents, an electro-mechanical drive (6) with a holder for the samples (1) and a control unit (7) on the base of a personal computer.

Synthesis is attained by the consistent dipping of the sample into the reagents solutions in accordance with a program. It is expected that in chemical cup (2) with a $\mathrm{M}_{1} \mathrm{~A}_{1}$ solution (e.g. $\left.\mathrm{La}\left(\mathrm{NO}_{3}\right)_{3}\right)$ at the surface of the substrate, the adsorption of the $\mathrm{M}_{1}^{\mathrm{n}+}$ cation takes place. Further, in cup (3) with water, the removal of the reagent's excesses and the reaction products takes place. At the processing stage in the $\mathrm{M}_{2} \mathrm{~A}_{2}$ solution in cup (4) (in our case it was $\mathrm{Na}_{x} \mathrm{NbO}_{y}$ ), the adsorption of the anion $\mathrm{A}^{\mathrm{m}-}$ occurs. Following rinsing with water and processing in cup (3), the removal of the reagent's excesses and reaction products is promoted. One

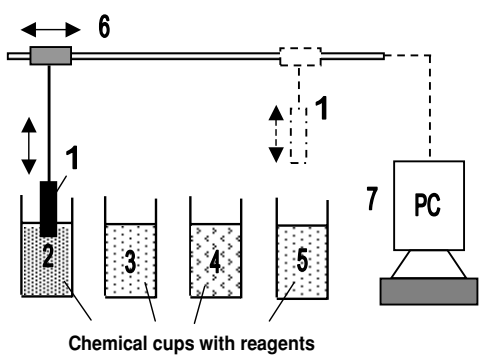

Figure 2. Schematic diagram of an aithomatic plant for the synthesis of metal oxides and noble metal layers using the SILD method: (1) holder with samples, (2-5) cups with chemical reagents for (2) cation adsorption, (4) transformation of precipitated substance into poorly soluble compounds, and for $(3,4)$ sample washing, (6) electro-mechanical drive for holder motion and (7) control unit on the base of the personal computer with the executive program.

deposition cycle is composed of treatment in all the cups. As a result of such a SILD cycle, at the work surface we observe the formation of one nanolayer of the synthesized substance (which is $\mathrm{La}_{x} / 3 \mathrm{NbO}_{y}$ in our case). Using the corresponding program, repeated iteration of the cycles can be organized. The deposition of the required layers with the necessary thickness in automatic mode is thus achieved.

The duration of each treatment depends on the time of every stage of the sorption and removal of excess reagents processes. For different materials, this time can be varied from 1-10 min. Ellipsometric measurements have shown that after each cycle a layer of peroxicomplexes or hydroxides of metals with thickness $0.4-1.5 \mathrm{~nm}$ can be deposited on the surface of the substrate $[9,12]$. The indicated thickness of the peroxicomplexes or hydroxides depends on the type of deposited metal. The dependence of the total film thickness on the number of deposition cycles follows a linear law [9]. Thus, this method allows the film thickness to be controlled with a high precision via the number of ionic deposition cycles. As can be seen from SEM images of various films synthesized by the SILD method (see figure 3), the formation of nanolayers takes place uniformly over the whole surface. As a result, the surface substrate has a continuous covering formed, whose morphology is determined by the nature of the synthesized material.

In our experiments, it was established that with relatively weak heating $\left(200-400{ }^{\circ} \mathrm{C}\right)$, these compounds release both water and peroxide oxygen, and transform into the corresponding oxides. This transition is clearly tracked in the transformation of a FTIR spectra [13, 14]. For $\mathrm{Ce}_{0.74} \mathrm{NbO}_{x} \cdot n \mathrm{H}_{2} \mathrm{O}$ films, synthesized at the $\mathrm{Si}$ surface, this process is reflected in figure 4 . The FTIR spectrum of the deposited layer (figure 4, curve 1) contains a broad absorption band at $3500-3200 \mathrm{~cm}^{-1}$ due to the stretching (v) modes of $\mathrm{OH}$ groups in both hydroxide and physisorbed water, a band at $1640 \mathrm{~cm}^{-1}$ typical of the bending $(\delta)$ mode of water, bands at 1487 and $1376 \mathrm{~cm}^{-1}$ due to the $\delta(\mathrm{OH})$ modes of niobium and cerium hydroxides, and a band at $846 \mathrm{~cm}^{-1}$ which is assigned to the $\mathrm{O}-\mathrm{O}$ stretches in the adsorbed peroxide species. After annealing the synthesized sample in air at $200{ }^{\circ} \mathrm{C}$ (figure 4 , curve 2), the intensity of the water bands decreases abruptly, whereas the peroxide band at $846 \mathrm{~cm}^{-1}$ vanishes. At the same 

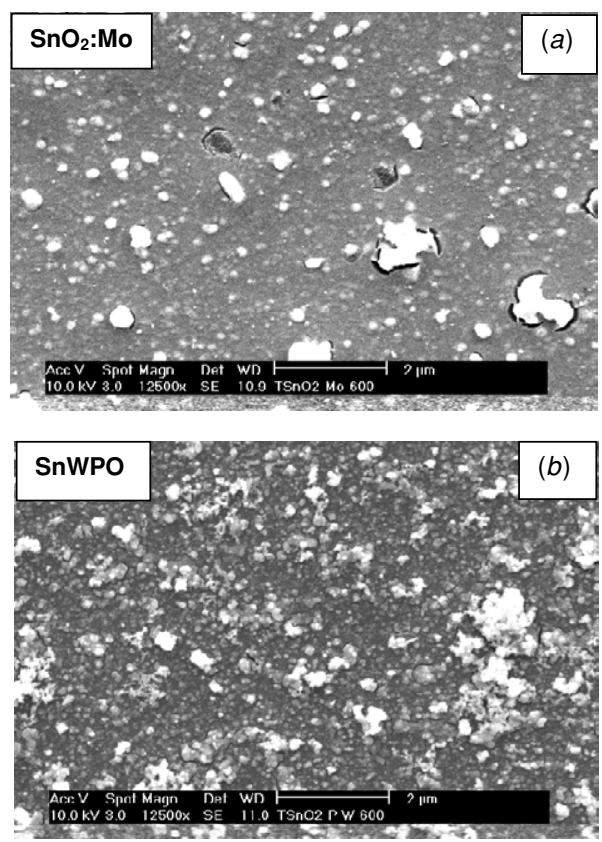

Figure 3. SEM images of (a) $\mathrm{SnO}_{2}: \mathrm{Mo}_{3-x}$ and (b) SnWPO films synthesized by SILD.

time, the $\delta(\mathrm{OH})$ bands in the $1500-1300 \mathrm{~cm}^{-1}$ region are still observed, disappearing only after sample annealing at $500{ }^{\circ} \mathrm{C}$ (figure 4, curve 4). The disappearance of the peroxide band undoubtedly indicates that the synthesized peroxide compound decomposes.

Some compounds and noble metals, which can be interesting for gas sensor applications, and which have been synthesized by the SILD method, are shown in table 1 . $\mathrm{SnO}_{2}, \mathrm{SnWPO}, \mathrm{La}_{x} \mathrm{NbO}_{3}$, and $\mathrm{Fe}_{2} \mathrm{O}_{3}$ are of interest as sensing materials. $\mathrm{CoO}, \mathrm{CuO}_{2-x}$, and $\mathrm{MnO}_{2}$ are of interest as additives for the modification of the gas sensing matrix, and the design of nanocomposites. While $\mathrm{Ag}, \mathrm{Pd}$ and $\mathrm{Au}$ are of interest as

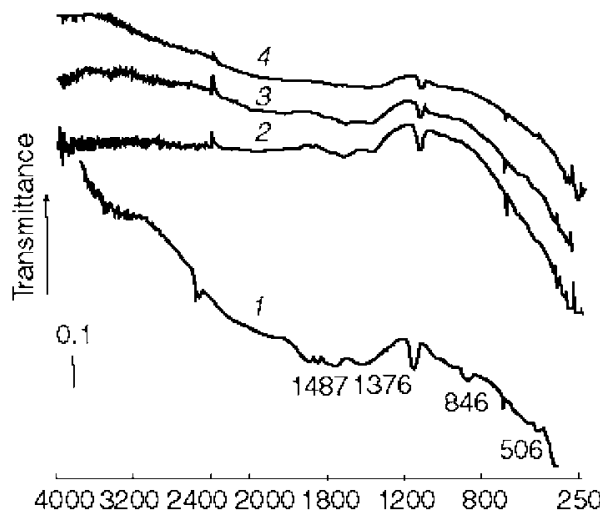

Figure 4. FTIR transmission spectra of $\mathrm{Ce}_{0.74} \mathrm{NbO}_{x} \cdot n \mathrm{H}_{2} \mathrm{O}$ nanolayers: (1) as-deposited at the surface of single crystalline silicon by 25 SILD cycles, and after annealing at (2) $200{ }^{\circ} \mathrm{C}$, (3) $300{ }^{\circ} \mathrm{C}$, and (4) $500^{\circ} \mathrm{C}$ over $30 \mathrm{~min}$.

surface catalyst additives used for the improvement of gas sensor parameters $[1,2,20]$. One should also pay attention to nanocomposites such as $\mathrm{SnO}_{2}-\mathrm{Au}$, which could be of interest not only as gas sensors, but also in heterogeneous catalysis (in particular low temperature $\mathrm{CO}$ oxidation [21]). Hetero polycompounds (HPC), which include SnWPO synthesized for the first time by us in [14], may be of interest for use as proton conductors, catalysts, and both electron- and ionexchangers [22].

\section{Advantages of SILD technology}

The main advantage of such a chemical route is conditioned by the fact that the reaction of cation metal adsorption during the second step of the deposition cycle is automatically stopped when monolayer coverage is attained. In this paper, the same principle is observed. This is intended to allow ionby-ion growth of the compound film via sequential addition of individual atomic layers.

Table 1. Metals and compounds synthesized by SILD.

\begin{tabular}{|c|c|c|c|c|}
\hline Material & Precursors & $\begin{array}{l}\text { Temperature for } \\
\text { transformation in } \\
\text { metal oxide }\left({ }^{\circ} \mathrm{C}\right)\end{array}$ & $\begin{array}{l}\text { Thickness of } \\
\text { one layer (nm) }\end{array}$ & Reference \\
\hline \multicolumn{5}{|l|}{ Oxides } \\
\hline $\mathrm{SnO}_{2}$ & $\mathrm{SnF}_{2}$ & $300-350$ & $0.5-1.5$ & [13] \\
\hline $\mathrm{CuO}_{2-\mathrm{h}}$ & $\begin{array}{l}\mathrm{Cu}\left(\mathrm{NH}_{3}\right)_{2} ; \mathrm{Cu}\left(\mathrm{NO}_{3}\right)_{2} \\
\mathrm{Cu}(\mathrm{Ac})_{2}\end{array}$ & $150-200$ & $0.3-1.5$ & {$[15]$} \\
\hline $\mathrm{CoOOH}$ & $\mathrm{CoSO}_{4}$ & & & [15] \\
\hline SnWPO & $\mathrm{SnCl}_{2}+\mathrm{H}_{3} \mathrm{PW}_{12} \mathrm{O}_{40}$ & $400-500$ & & [14] \\
\hline $\mathrm{La}_{x} \mathrm{NbO} 3$ & $\mathrm{La}(\mathrm{Ac})_{3}+\mathrm{Nb}(\mathrm{OH})_{5} \mathrm{H}_{2} \mathrm{O}_{2}$ & $350-400$ & $\sim 0.6$ & [9] \\
\hline $\mathrm{MnO}_{2}$ & $\mathrm{MnCl}_{2} ; \mathrm{KMnO}_{4}$ & & $\sim 1.0$ & {$[15-17]$} \\
\hline $\mathrm{CeO}_{2}$ & $\mathrm{Ce}\left(\mathrm{NO}_{3}\right)_{3} ; \mathrm{Ce}(\mathrm{Ac})_{3}$ & $300-350$ & $0.3-1.5$ & {$[12,17]$} \\
\hline $\mathrm{Fe}_{2} \mathrm{O}_{3}$ & $\left(\mathrm{NH}_{4}\right)_{2}\left[\mathrm{Fe}\left(\mathrm{SO}_{4}\right)_{2}\right]$ & $250-300$ & $0.3-0.5$ & [18] \\
\hline \multicolumn{5}{|l|}{ Noble metals } \\
\hline $\mathrm{Ag}$ & $\mathrm{AgNO}_{3}$ & & & \\
\hline $\mathrm{Pd}$ & $\mathrm{PdCl}_{2}$ & & & \\
\hline $\mathrm{Au}$ & $\mathrm{HAuCl}_{4}$ & & & \\
\hline \multicolumn{5}{|l|}{ Nano-composites } \\
\hline $\mathrm{SnO}_{2}-\mathrm{Au}$ & $\mathrm{SnCl}_{2}+\mathrm{HAuCl}_{4}$ & & & \\
\hline $\mathrm{SnO}_{2}-\mathrm{MoO}_{3-x}$ & $\mathrm{SnCl}_{2}+\mathrm{Na}_{2} \mathrm{MoO}_{4}$ & & & \\
\hline $\mathrm{MnO}_{2}-\mathrm{Ag}$ & $\mathrm{AgNO}_{3}+\mathrm{MnCl}_{2}$ & & & [19] \\
\hline
\end{tabular}


This synthesis can be carried out under 'mild' conditions, at room temperature, in a simple apparatus, using simple deposition, inexpensive precursors and solutions with a $\mathrm{pH}$ near to neutral. The SILD method is a clean and innovative process with low emissions, is readily available, and has low maintenance costs. Formation of the dilute solutions including cation- and anion-reagents and stripping of the water after the SILD synthesis can be easily carried out by simple mixing and filtration. This method does not require an electrical current. Therefore, the particles used for surface modification can be in the solution in a suspension state. As a result, this procedure allows both nanolayers and nanoclusters of noble metals and metal oxides to be deposited on the developed surface, e.g. on the surface of porous materials and disperse grains (powders).

The SILD method does not possess high deposition rates in comparison with other chemical methods of deposition, such as electrochemical deposition, chemical deposition, etc [3]. However, this property is not required for surface modification, especially by nanoclusters and nanolayers. Precise monitoring of both the size and composition of deposited clusters is more important for surface modification. This gives this method great advantages in comparison with many other methods used in the surface modification of metal oxides. Therefore, the SILD-based technique will have the potential as a new sensor technology for the design of new nanoscale and innovative materials with modified surface structures. This technology may be applied in the fabrication of various catalysts, new surface coatings, advanced drug design, smart materials, etc.

\section{Experimental study of the structure and gas sensing properties of metal oxide films deposited or modified by SILD}

Only a small number of compounds synthesized by the SILD method have been tested as materials for gas sensors. At the present time, we were only able to conduct a detailed study of the gas sensing properties of $\mathrm{SnO}_{2}$ films, synthesized and modified by the SILD method. However, even current information allows us to make some important estimations of the advantages and shortcomings of the SILD technology being discussed. $\mathrm{SnO}_{2}$ has been one of the most widely studied metal oxides during the last decade due to its gas sensor and catalysis applications [1, 2, 23], and therefore $\mathrm{SnO}_{2}$ was selected as the base material for showing the implementation of the SILD technology for gas sensor applications.

\subsection{Experimental details of structure and gas sensing characterization of SILD synthesized materials}

The structural characterization of the films deposited by SILD was carried out using XRD (x-ray diffraction) using a Rigaku Rotaflex with $\mathrm{Cu} \mathrm{K}_{\alpha}$ radiation, SEM (scanning electron microscopy) using a XL30 Philips FEG, and AFM (atomic force microscopy) using a Nanostation II. The FTIR (fuorie transmission infra red) spectra were obtained with a FTIR Perkin-Elmer $1760 \times$ spectrometer equipped with a DTGS detector. The spectra are averages of 20-50 scans at a resolution of $4 \mathrm{~cm}^{-1}$. The $\mathrm{UV} / \mathrm{Vis}$ (ultraviolet/visible) spectra were measured with a Lambda-9 Perkin-Elmer spectrophotometer at a scanning rate of $50 \mathrm{~nm} \mathrm{~min}{ }^{-1}$ and slit program of $2 \mathrm{~nm}$.
$\mathrm{SnO}_{2}$ films used for surface modification with the SILD method were deposited by spray pyrolysis from a $\mathrm{SnCl}_{4}$-water solution at $T_{\mathrm{pyr}}=420^{\circ} \mathrm{C}$. Films had thicknesses of $40-50 \mathrm{~nm}$. Peculiarities of the deposition technology and the structure of the $\mathrm{SnO}_{2}$ films were previously described in [23-25].

The gas sensing characteristics were tested in steady state and transient modes in a flow-type measurement cell having a volume of $\sim 0.3 \mathrm{~cm}^{-3}$. $\mathrm{CO}(1000 \mathrm{ppm}), \mathrm{H}_{2}$ (5000 ppm) and ozone ( $1 \mathrm{ppm})$ were used as testing gases. DC (direct current) electrical measurements were carried out in both humid (35-45\% RH) and dry (1-2\% RH) atmospheres. The gas response was calculated as a resistance ratio $R$ (ozone) $/ R$ (air) for ozone detection, and $R$ (air) $/ R(\mathrm{CO}$, $\mathrm{H}_{2}$ ) for $\mathrm{CO}$ and $\mathrm{H}_{2}$ detection. Response and recovery times were estimated at the 0.9 level of the steady state magnitude of the film resistance measured after changing the atmosphere in the measurement cell. Prior to the gas sensing experiments, the metal oxide films were annealed in air at $T_{\text {an }}=500{ }^{\circ} \mathrm{C}$ for $30 \mathrm{~min}$. This treatment was used to obtain better stability of the gas sensing characteristics of the fabricated devices.

\subsection{Peculiarities of $\mathrm{SnO}_{2}$ synthesis and surface modification by SILD}

Single-crystalline $\mathrm{Si}$ and sintered quartz were used as substrates for the deposition of the $\mathrm{SnO}_{2}$ films. Freshly prepared $0.01 \mathrm{M}$ solutions of $\mathrm{SnF}_{2}$ were used as precursors during the $\mathrm{SnO}_{2}$ SILD. The samples were then washed with distilled water to remove the excess salt, and subsequently treated with a $1.5 \mathrm{M} \mathrm{H}_{2} \mathrm{O}_{2}$ solution. After this treatment, the excess $\mathrm{H}_{2} \mathrm{O}_{2}$ was removed by heating in air at $T \sim 80-100{ }^{\circ} \mathrm{C}$. Each treatment step had a duration of $0.5 \mathrm{~min}$.

The reactants used in the synthesis of $\mathrm{Ag}^{\mathrm{O}}$ were an aqueous $0.01 \mathrm{M}$ solution of $\mathrm{AgNO}_{3}$, together with an aqueous $0.1 \mathrm{M}$ solution of hydrogen peroxide with additions of $\mathrm{KOH}$ or ammonia $(\mathrm{pH}=9)$. $\mathrm{Pd}^{\circ}$ layers were made by repeated treatment of the $\mathrm{SnO}_{2}$ films with $\mathrm{PdCl}_{2}(0.001 \mathrm{M})$ solutions in ethyl. One Pd deposition cycle also included a rinse in distilled water and treatment of the $\mathrm{SnO}_{2}$ samples with adsorbed Pdions in alcohol solutions heated to $50{ }^{\circ} \mathrm{C}$.

\subsection{Structural properties of metal oxide films deposited by SILD}

During the study of the structure of metal oxides deposited using the SILD method, it was established that as-deposited films are amorphous or a finely dispersed formation of hydroxide or hydrated metal oxide-based compounds [13, 14]. In the case of $\mathrm{SnO}_{2}$ deposition, such compounds are $\mathrm{Sn}(\mathrm{OH})_{4}$ or $\mathrm{SnO}_{2} \cdot n \mathrm{H}_{2} \mathrm{O}$. The broad band on the FTIR transmission spectra centred around $3250 \mathrm{~cm}^{-1}$ is a confirmation of this conclusion. The main part of the coordinated water, which can be responsible for the appearance of this band, has already been removed from the film after annealing at $T_{\text {an }}=200{ }^{\circ} \mathrm{C}$. Results of the FTIR and XPS studies of the deposited films, presented in [13, 14], have shown that after annealing in an oxygen containing atmosphere, hydroxides transform to oxide forms. However, traces of the hydroxyl groups remain even after annealing at $T_{\text {an }}=500{ }^{\circ} \mathrm{C}$.

A high degree of agglomeration is another peculiarity of metal oxides deposited from aqueous solutions. AFM 


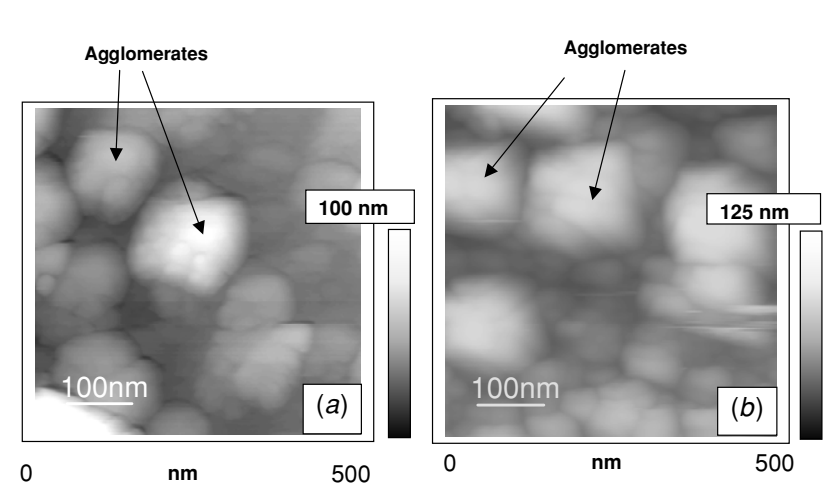

Figure 5. AFM images of (a) $\mathrm{SnO}_{2}$ and (b) SnWPO films deposited by $\operatorname{SILD}\left(T_{\mathrm{an}}=600^{\circ} \mathrm{C}\right)$.

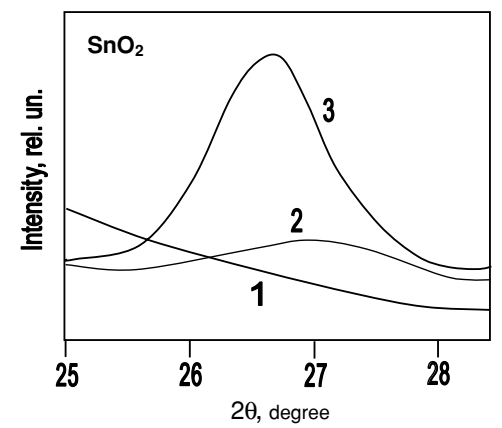

Figure 6. The influence of thermal annealing on the shape of smoothed XRD patterns of $\mathrm{SnO}_{2}$ films synthesized by SILD. XRD patterns were measured in the region of the main peak, corresponding to x-ray diffraction on the $\mathrm{SnO}_{2}(110)$ plane: (1) as-deposited, (2) $T_{\text {an }}=600{ }^{\circ} \mathrm{C}$ and (3) $T_{\text {an }}=800^{\circ} \mathrm{C}$.

and SEM images have shown that the undoped $\mathrm{SnO}_{2}$ films deposited by the SILD method consist of spherical agglomerates and have a very high roughness compared to the roughness of tin oxide films deposited by standard methods of film deposition (see figure 5). This is the same as other metal oxides deposited from aqueous solutions. The average agglomerate size increased with increasing number of deposition cycles, corresponding to increased overall film thickness. For example, for $\mathrm{SnO}_{2}$ films deposited by SILD, agglomerate sizes increased from 20 to $300 \mathrm{~nm}$ when we increased the number of deposition cycles from 10 to 40 . It indicates that the growth of the metal oxide films during deposition from aqueous solutions takes place through the growth of the agglomerates.

According to XRD measurements, these agglomerates are finely dispersed formations. On XRD patterns of as-deposited films, no diffraction peaks were observed. XRD peaks start to appear only after annealing at $T_{\text {an }}>600^{\circ} \mathrm{C}$. This phenomenon can be clearly observed for the most intensive XRD peak, corresponding to diffraction at the $\mathrm{SnO}_{2}(110)$ surface (see figure 6). The $\mathrm{XRD}$ patterns of $\mathrm{SnO}_{2}$ films after annealing at $T=800{ }^{\circ} \mathrm{C}$ were typical of polycrystalline materials without a preferred orientation. When $T_{\text {an }}$ increases, the XRD peaks become narrower and more intense. This observed evolution indicates crystallite growth during heat treatment. However, this growth is not strong in comparison with films deposited by sputtering or laser ablation. For example, even after annealing at $T=800{ }^{\circ} \mathrm{C}$, the average size of the crystallites did not exceed 6-7 nm. This was an unexpected result. Apparently, either uncontrolled impurities, or products of reactions (taking place on the grain surface during the SILD process) inhibit the grain growth during the thermal treatment process.

One should note that such structural peculiarities (high levels of agglomeration and small grain size) for $\mathrm{SnO}_{2}$ films have been confirmed in the research of the structural properties of other metal-oxide nanocomposite films such as $\mathrm{SnO}_{2}$ $\mathrm{MoO}_{3-x}$ and SnWPO, synthesized by the SILD method [14] (see figure $5(b)$.

Both the level of agglomeration of the films obtained by the SILD method and the agglomerate porosity can be controlled. We are confident that the introduction of various additives in the solution for SILD could sufficiently change the formation mechanism and the microstructure of the metal oxide matrix. As an example of such an influence, one can consider the SEM images of $\mathrm{SnO}_{2}, \mathrm{SnO}_{2}: \mathrm{MoO}_{3-x}$, and $\mathrm{SnO}_{2}: \mathrm{Pd}$ films, synthesized by the SILD method, shown in figure 7. However, this research has just begun, and therefore it is too early to comment on any established regularities.

\subsection{Gas sensing properties of $\mathrm{SnO}_{2}$ films deposited by $\mathrm{SILD}$}

Some results of the gas response testing are presented in figure 8. It is seen that the $\mathrm{SnO}_{2}$ films deposited by SILD have a high gas response to ozone. It was established that the reaction of ozone detection is fast with a response time of 2-3 s at $T_{\text {oper }}=275^{\circ} \mathrm{C}$. These films have a better gas sensitivity to ozone than the $\mathrm{SnO}_{2}$-based ceramics prepared by the sol-gel method in [26]. Films deposited by SILD are also sensitive to reducing gases such as $\mathrm{CO}, \mathrm{H}_{2}, \mathrm{CH}_{4}$. More detailed information about gas response to reducing and oxidizing gases may be found in [13].

We suppose that both the high speed of response and the high sensitivity to ozone (in spite of the high level of agglomeration) are conditioned by the fact that the gas sensing element of the $\mathrm{SnO}_{2}$-based gas sensing matrix, formed by the SILD method, is an interagglomerate contact, not an intercrystalline one.

\subsection{Gas sensing properties of $\mathrm{SnO}_{2}$-based sensors with surface modification}

The surface modification of metal oxides is becoming one of the most promising methods of optimization of gas sensing properties of conductometric solid state gas sensors [1, 2, 27]. Therefore, we have estimated possibilities of the application of SILD technology in this area. For these purposes we have studied the gas sensing properties of nanoscaled $\mathrm{SnO}_{2}$ films modified by the SILD method.

4.5.1. $\mathrm{SnO}_{2}$ films with surface modification by noble metals. The results of the influence of surface modifications of $\mathrm{SnO}_{2}$ films by $\mathrm{Pd}$ and $\mathrm{Ag}$ on the gas sensing characteristics of $\mathrm{SnO}_{2}$ based gas sensors are shown in figures 9 and 10 .

These results show that $\mathrm{Pd}$ and $\mathrm{Ag}$ deposition at the $\mathrm{SnO}_{2}$ surface promotes the increase of the gas response to reducing gases by more than five to ten times. This demonstrates 

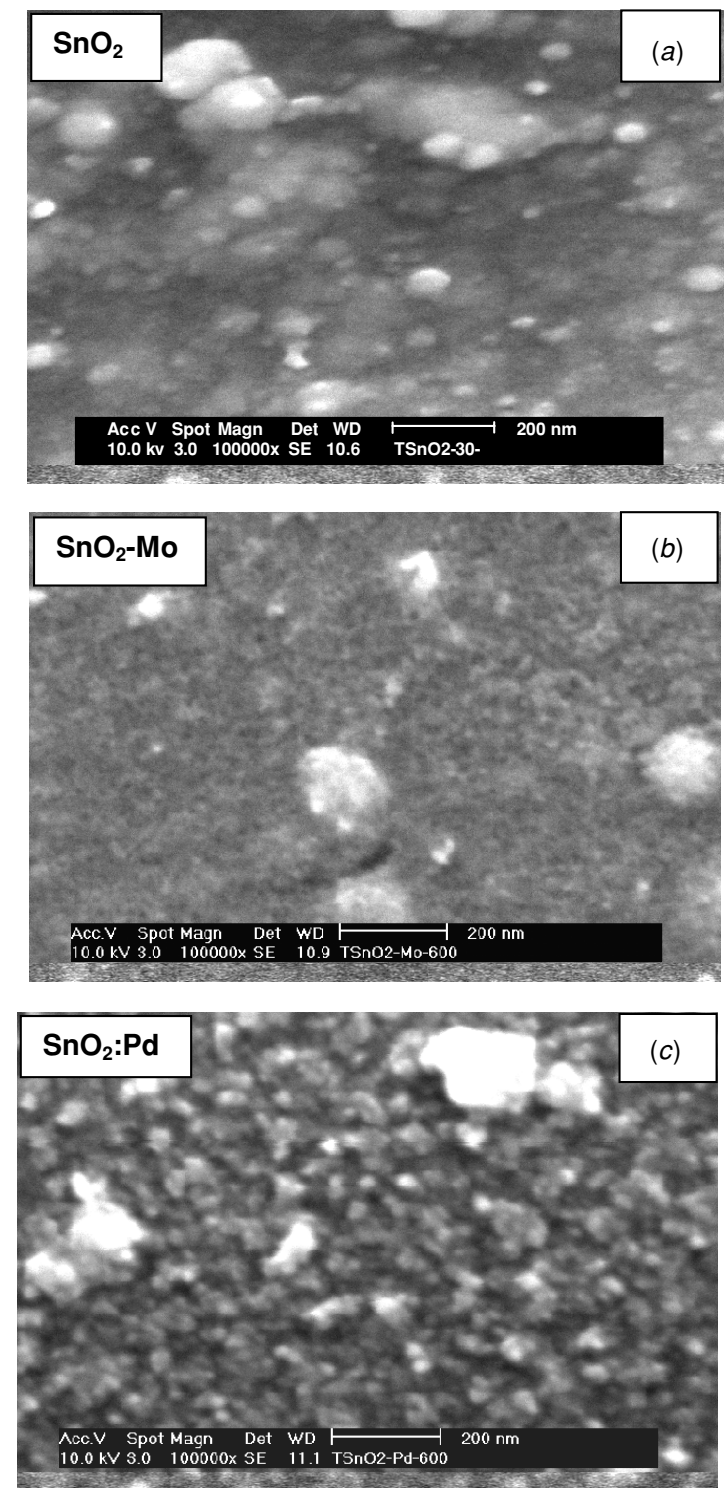

Figure 7. SEM images of: $(a) \mathrm{SnO}_{2},(b) \mathrm{SnO}_{2}: \mathrm{MoO}_{2}$, and (c) $\mathrm{SnO}_{2}: \mathrm{Pd}$ films synthesized by the SILD method at the surface of an oxidized $\mathrm{Si}$ (111) substrate.

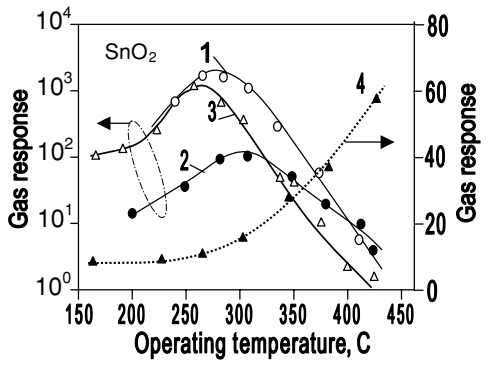

Figure 8. Temperature dependences of the $\mathrm{SnO}_{2}$ gas response to (1-3) 1 ppm ozone and (4) $5000 \mathrm{ppm} \mathrm{H}_{2}$. Films were deposited by the SILD method using: (1) 20, (2) 30, (3, 4) 40 deposition cycles.

that this method of surface modification can indeed be used for improvement of the parameters of the $\mathrm{SnO}_{2}$-based gas sensors. For both $\mathrm{Pd}$ and $\mathrm{Ag}$, an optimal surface coverage that gives a maximum increase of the gas response exists.

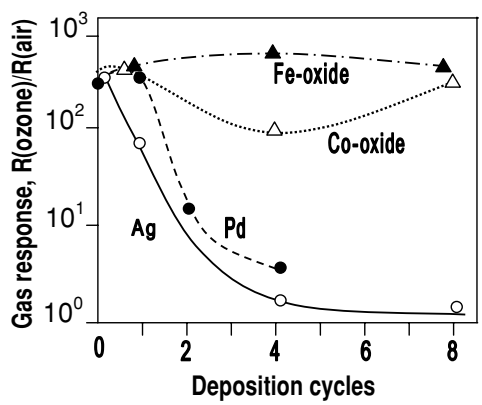

Figure 9. Influence of $\mathrm{SnO}_{2}$ surface modification by noble metals (such as $\mathrm{Ag}$ and $\mathrm{Pd}$ ) and by metal oxides of $\mathrm{Fe}$ and $\mathrm{Co}$ on the gas response to $\sim 1 \mathrm{ppm}$ ozone, $T_{\text {oper }}=275^{\circ} \mathrm{C}$.

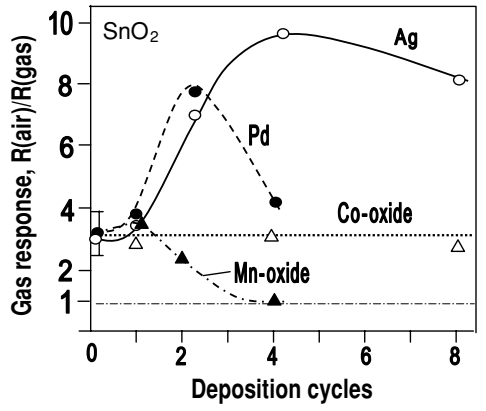

Figure 10. Influence of $\mathrm{SnO}_{2}$ surface modification by noble metals (such as $\mathrm{Ag}$ and $\mathrm{Pd}$ ) and by metal oxides of $\mathrm{Mn}$ and $\mathrm{Co}$ on the gas response to $1000 \mathrm{ppm} \mathrm{CO}, T_{\text {oper }}=425^{\circ} \mathrm{C}$.

For $\mathrm{Pd}$, the maximum gas response to both $\mathrm{H}_{2}$ and $\mathrm{CO}$ detection is obtained after two cycles of deposition. For $\mathrm{Ag}$, the optimum is observed at a greater extent of surface coverage, and this optimum is not consistent for both $\mathrm{H}_{2}$ and $\mathrm{CO}$ detection. For $\mathrm{CO}$ detection, the maximum gas response is obtained after four cycles of $\mathrm{Ag}^{\mathrm{O}}$ deposition. Furthermore, the position of the optimum depends on the operating temperature, and shifts to the range with less $\mathrm{Ag}$ coverage as $T_{\text {oper }}$ decreases.

We suppose that the observed distinction in the behaviour of $\mathrm{SnO}_{2}: \mathrm{Pd}$ and $\mathrm{SnO}_{2}: \mathrm{Ag}$ samples is in accordance with the features of the Pd and $\mathrm{Ag}$ clusters formed. $\mathrm{Ag}$ tends to form big clusters on the $\mathrm{SnO}_{2}$ surface at relatively low temperatures. As a result, even with the same amount of deposited material, the Ag clusters should be much less dense at the $\mathrm{SnO}_{2}$ surface in comparison with the Pd clusters. Therefore, to obtain the same density of $\mathrm{Ag}$ and Pd surface clusters, it is necessary to deposit much more Ag than Pd.

Another interesting effect is the influence of the surface modification by the $\mathrm{Pd}$ and $\mathrm{Ag}$ on the sensor responses to ozone. The presence of Pd, and especially $\mathrm{Ag}$, additives at the $\mathrm{SnO}_{2}$ surface sharply suppresses the gas response to ozone. It was determined that after only two deposition cycles of $\mathrm{Pd}$ or $\mathrm{Ag}$, the gas response to ozone declines by more than 20 40 times for $\mathrm{SnO}_{2}$ :Pd samples, and by more than 100 times for $\mathrm{SnO}_{2}$ :Ag samples. However, the sensitivity to reducing gases remains at the same level, and can even increase. Such a combination of properties allows us to use SILD in the formation of catallytically active filters. In particular, nanolayers of $\mathrm{Pd}$ and $\mathrm{Ag}$ are perfect filters for oxidizing 
gases. They promote the improvement of the exploitation of the reducing gas sensor parameters during atmospheric work where ozone is present. The influence of ozone in the surrounding atmosphere on the output signal of $\mathrm{SnO}_{2}$-based sensors with surface modification by Pd or Ag nanolayers will be weaker than for unmodified sensors.

The high surface diffusion of silver at increased temperatures could cause a drift of characteristics that could limit possible areas of such sensor applications. They are not applicable for metrological devices. However, silver coverings are adequate for use in sensors for alarm systems, where characteristic stability requirements are lower. In addition, we suppose that artificial ageing before commencing the exploitation of the sensors on the base of $\mathrm{SnO}_{2}: \mathrm{Ag}$ could appreciably reduce the negative effect of the above mentioned Ag property.

4.5.2. $\mathrm{SnO}_{2}$ films with surface modification by metal oxides. The first results of research in this direction were presented in [15], and some are shown in figures 9 and 10. By analysing the gas responses of $\mathrm{SnO}_{2}$ films with an additional oxide layer of transition metals such as $\mathrm{Fe}, \mathrm{Mn}, \mathrm{Cu}$ and $\mathrm{Co}$, we have established that, by using SILD technology, it is possible to deposit additional layers of other oxides on the surface of nanostructural layers of metal oxides. Therefore, we are permitted not only to modify the characteristics of basic metal oxides, but also to create various hetero-structures. Results of research presented in $[27,28]$ have shown that sensors on the base of hetero-structures at certain conditions could possibly have unique properties, which cannot be realized while using common metal oxides and standard approaches.

\section{Conclusions}

It was shown that SILD technology is an effective method for preparing gas sensing films. SILD technology allows porous rough metal oxide films with nanoscale crystallites of sizes smaller than 6-7 $\mathrm{nm}$ to be deposited. As a result, films deposited by SILD may have a high gas response to both oxidizing and reducing gases. Films are agglomerated, with the average size of agglomerates ranging from 20-300 $\mathrm{nm}$.

SILD technology can also be used for the surface modification of metal oxides. This method permits a controlled deposition of nanolayers and nanoclusters of noble metals, such as Pd and $\mathrm{Ag}$, and various metal oxides onto the $\mathrm{SnO}_{2}$ surface. Surface modification of $\mathrm{SnO}_{2}$ films by $\mathrm{Pd}$ and $\mathrm{Ag}$ with SILD technology allows gas response of $\mathrm{SnO}_{2}$ based gas sensors to reducing gases to be improved, and the sensitivity to oxidizing gases such as ozone to be depressed. This property of $\mathrm{SnO}_{2}$ films, modified by $\mathrm{Pd}$ and $\mathrm{Ag}$, can be used to increase the selectivity of the $\mathrm{SnO}_{2}$-based gas sensors. Given nanolayers may act as filters for oxidizing gases, promoting the improvement of exploitation parameters of the sensors of reducing gases working in real conditions, when the appearance of either ozone or nitrogen dioxide in the atmosphere is possible. Metal oxide layers deposited at the surface of a gas sensing matrix may also be effective filters for the improvement of gas sensing characteristics.

The use of SILD technology in forming both passive and catalytically active filters creates an interesting proposal given the behaviour of these coverings. Important advantages for such filters would be their high porosity and high surface area, which improve their effectiveness. The benefits of the suggested technology may be considerably increased by being able to form such coverings at room temperature. Oxides formed by the SILD method could possibly be used as precoats in catalytically active filters, by separating the noble metals from the gas sensing metal oxides. The effectiveness of such a possibility has been discussed in [29].

The presented technology is also of interest for sensors on the base of porous materials such as $\mathrm{Si}$, as the surface modification of porous semiconductors promotes a considerable surface reactivity.

SILD technology could also possibly be successfully implemented into the fabrication of other types of catalytically active filters designed, for example, for the reduction of pollutant emissions from various combustion engines. Both the accessibility and the simplicity of the technology, in addition to the opportunity to deposit catalytically active materials on the developed surfaces, used as a support for heterogeneous catalysts, may contribute to the successful advancement of SILD technology in this market.

\section{Acknowledgments}

This work was supported by the Civilian Research Development Foundation (CRDF) in the framework of a CGP Program (grant MO-E2-2588-CH-04). The authors are thankful to Dr V Brinzari and I Boris for assistance in the structural and gas sensing characterization of the studied materials, and also to Dr L Gulina for the synthesis of the series of samples.

\section{References}

[1] Yamazoe N, Kurokawa Y and Seiyama T 1983 Effects of additives on semiconductor gas sensors Sensors Actuators 4 283-9

[2] Kohl D 1990 The role of noble metals in the chemistry of solid-state gas sensors Sensors Actuators B 1 158-65

[3] Niesenand T P and De Guire M R 2001 Review: deposition of ceramic thin films at low temperatures from aqueous solutions J. Electroceram. 6 169-207

[4] Tolstoy V P, Bogdanova L P and Mityukova G Y 1986 The method of $\mathrm{MnO}_{2}$ layer synthesis USSR Patent N. 1386600

[5] Nicolau Y F 1985 Solution deposition of the thin solid films by SILAR Appl. Surf. Sci. 22/23 1061-74

[6] Nicolau Y F, Dupuy M and Brunel M 1990 ZnS, CdS, and $\mathrm{Zn}_{x} \mathrm{Cd}_{1-x} \mathrm{dS}$ thin films deposition by the SILAR J. Electrochem. Soc. 137 2915-24

[7] Tolstoy V P 2003 Reactions of layer by layer deposition at the solution-solid interface: possible classification Chemistry of Solid State. Chemical Problems of New Material Synthesis ed I V Murin (St Petersburg: SPGU) pp 121-67 (in Russian)

[8] Tolstoy V P 2006 Successive ionic layer deposition. An application in nanotechnology Russ. Chem. Rev. 75 161-75

[9] Tolstoy V P 1997 The peroxide route of the successive ionic layer depostion procedure for synthesizing nanolayers of metal oxides, hydroxides and peroxides Thin Solid Films 307 10-13

[10] Tolstoy V P 1993 Synthesis of superthin $\mathrm{SnO}_{2} n \mathrm{H}_{2} \mathrm{O}$ layers on the surface of Si by layer by layer ionic deposition Russ. J. Appl. Chem. 38 1146-8 (in Russian)

[11] Puigdomenech I http://www.kemi.kth.se/medusa 
[12] Tolstoy V P and Enrlich A G 1997 The synthesis of $\mathrm{CeO}_{2+\mathrm{n}} n \mathrm{H}_{2} \mathrm{O}$ nanolyers on silicon and fused-quartz surfaces by the successive ionic layer deposition technique Thin Solid Films 307 60-64

[13] Korotcenkov G, Macsanov V, Tolstoy V, Brinzari V, Schwank J and Faglia G 2003 Structural and gas response characterization of nano-size $\mathrm{SnO}_{2}$ films deposited by SILD method Sensors Actuators B 96 602-9

[14] Tolstoy V P, Gulina L B, Korotcenkov G S and Brinzari V I 2003 Synthesis of nanolayers of hybrid-type hydroxo- $\left(\mathrm{Sn}_{x} \mathrm{O}_{y} \mathrm{H}_{z}\right)$ and heteropoly- $\left(\mathrm{H}_{x} \mathrm{PW}_{y} \mathrm{O}_{z}\right)$ compounds on silica surfaces by successive ionic layer deposition method Appl. Surf. Sci. 221 197-202

[15] Korotcenkov G, Macsanov V, Brinzari V, Tolstoy V, Schwank J, Cornet A and Morante J 2004 Influence of Cu-, $\mathrm{Fe}-$, Co-, and Mn-oxide nanoclusters on sensing behavior of $\mathrm{SnO}_{2}$ films Thin Solid Films 467 209-14

[16] Tolstoy V P, Murin I V and Reller A 1997 The synthesis of $\mathrm{Mn}(\mathrm{IV})$ oxide nanolayers by the successive ionic layer deposition Appl. Surf. Sci. 112 255-7

[17] Tolstoy V P 2002 Synthesis by SILD of $\mathrm{Ce}_{4} \mathrm{MnO}_{x} n \mathrm{H}_{2} \mathrm{O}$ nanolayers Russ. J. Appl. Chem. 75 673-6 (in Russian)

[18] Tolstoy V P 1999 The synthesis of $\mathrm{FeOOH}$ nanolayers on the surface of $\mathrm{SiO}_{2}$ using layer by layer method Russ. J. Appl. Chem. 72 1259-61 (in Russian)

[19] Tolstoy V P and Tostobrov E V 2004 Synthesis of $\mathrm{Ag}_{r}^{0} \cdot \mathrm{MnO}_{2} \cdot n \mathrm{H}_{2} \mathrm{O}$ metal oxide nanocomposites by method of ionic stratifying Russ. J. Gen. Chem. 74 360-3 (in Russian)
[20] Meixner H and Lampe U 1996 Metal oxide sensors Sensors Actuators B 33 198-202

[21] Grisel R J and Nieuwenhuys B E 2001 Selective oxidation of CO over support Au catalysts J. Catal. 199 48-59

[22] Pop T 1983 Hetero-Isopolyoxolates of Metals (Berlin: Springer)

[23] Korotcenkov G, Brinzari V, DiBattista M, Schwank J and Vasiliev A 2001 Peculiarities of $\mathrm{SnO}_{2}$ thin film deposition by spray pyrolysis for gas sensor application Sensors Actuators B 77 244-52

[24] Korotcenkov G, DiBattista M, Schwank J and Brinzari V 2000 Structural characterization of $\mathrm{SnO}_{2}$ gas sensing films deposited by spray pyrolysis J. Mater. Sci. Eng. B 77 33-9

[25] Korotcenkov G, Cornet A, Rossinyol E, Arbiol J, Brinzari V and Blinov Y 2005 Faceting characterization of $\mathrm{SnO}_{2}$ nanocrystals deposited by spray pyrolysis from $\mathrm{SnCl}_{4}-5 \mathrm{H}_{2} \mathrm{O}$ water solution Thin Solid Films 471 310-9

[26] Sauter D, Weimar U, Noetzel G, Mitrovics J and Gopel W 2000 Development of modular ozone sensor system for application in practical use Sensors Actuators B 69 1-9

[27] Yuanda W, Maosong T, Xiuli H, Yushu Z and Guorui D 2001 Thin film sensors of $\mathrm{SnO}_{2}-\mathrm{CuO}-\mathrm{SnO}_{2}$ sandwich structure to $\mathrm{H}_{2} \mathrm{~S}$ Sensors Actuators B 79 187-91

[28] Korotcenkov G 2005 Gas response control through structural and chemical modification of metal oxides: State of the art and approaches Sensors Actuators B 107 209-32

[29] Pijolat C, Viricelle J P, Tournier G and Montmeat P 2005 Application of membranes and filtering films for gas sensors improvements Thin Solid Films 490 7-16 